\title{
Screening and identification of serum proteomic biomarkers for gastric adenocarcinoma
}

\author{
CHIBO LIU ${ }^{1}$, CHUNQIN PAN $^{1}$ and YONG LIANG ${ }^{2}$ \\ Departments of ${ }^{1}$ Clinical Laboratory, and ${ }^{2}$ Tumorology, Taizhou Municipal Hospital, Taizhou, Zhejiang, P.R. China
}

Received January 10, 2012; Accepted February 20, 2012

DOI: 10.3892/etm.2012.515

\begin{abstract}
The aim of the present study was to screen for possible serum biomarkers for gastric adenocarcinoma. Surface-enhanced laser desorption ionization time of flight mass spectrometry (SELDI-TOF-MS) was used to screen serum samples from 109 cases of gastric adenocarcinoma and 106 control subjects (60 healthy subjects, 30 patients with chronic superficial gastritis and 16 cases of chronic atrophic gastritis). The differentially expressed protein peaks were selected and isolated using high performance liquid chromatography (HPLC) and processed with enzyme prior to liquid chromatography-mass spectrometry tandem mass spectrometry (LC-MS/MS) analysis and data mining with software XCalibur program components BioWorks 3.2. Among the gastric cancer cases, three differentially expressed protein peaks were selected as potential serum biomarkers: the $\mathrm{m} / \mathrm{z}$ peaks at 5,906.5 showed increased expression $(8.53 \pm 4.33$ in the cancer group, and $0.88 \pm 0.31$ in the control group); the $\mathrm{m} / \mathrm{z}$ peaks at $6,635.7$ and $8,716.3$ showed decreased expression $(6.54 \pm 2.44$ and $0.93 \pm 0.29$, respectively, in the cancer group and $17.56 \pm 4.43$ and $2.16 \pm 0.98$, respectively, in the control group) $(\mathrm{P}<0.01)$. The $\mathrm{m} / \mathrm{z}$ peaks at $5,906.5,6,635.7$ and 8,716.3, were identified as fibrinogen $\alpha$-chain, apolipoprotein A-II and apolipoprotein C-I. The combined use of the three biomarkers distinguished the cancer group patients from the control group samples at a sensitivity of $93.85 \%(61 / 65)$ and a specificity of $94.34 \%$ (50/53). In conclusion, fibrinogen $\alpha$-chain, apolipoprotein A-II and apolipoprotein C-I were identified as potential markers for gastric cancer and appear to have diagnostic value for clinical applications.
\end{abstract}

Correspondence to: Dr Yong Liang, Department of Tumorlogy, Taizhou Municipal Hospital, Taizhou, Zhejiang, P.R. China

E-mail: liangy@yahoo.cn

Dr Chibo Liu, Department of Clinical Laboratory, Taizhou Municipal Hospital, Taizhou, Zhejiang, P.R. China

E-mail: chibo_liu@163.com; liuchibo@126.com

Key words: serum, proteome, surface-enhanced laser desorption ionization time of flight mass spectrometry, biomarker, gastric cancer, fibrinogen $\alpha$-chain, apolipoprotein A-II, apolipoprotein C-I

\section{Introduction}

Gastric adenocarcinoma is a common gastrointestinal malignant tumor, accounting for $23.2 \%$ of cancer-related deaths in China (approximately 16 million individuals) $(1,2)$. At present, the clinical diagnosis of gastric adenocarcinoma mainly relies on physical and histological examinations, which are accurate only for middle- or late-stage cases. Therefore, many patients are diagnosed at a late stage of the disease. Biochemical markers such as carcinoembryonic antigen, carbohydrate antigen 19-9 and carbohydrate antigen 125 are used as markers for diagnosis; however they are non-specific and lack adequate sensitivity (3-6). The present study aimed to design a new diagnostic system with high sensitivity and specificity for early-stage gastric cancer detection. We employed a newly emerging technique, surfaceenhanced laser desorption ionization time-of-flight mass spectrometry (SELDI-TOF-MS) (7-12), to analyze the serum proteome from healthy volunteers, gastric cancer patients and gastritis patients, and to screen for specific protein biomarkers for gastric cancer (13-15).

\section{Materials and methods}

Clinical data. One hundred and nine gastric cancer patients (males 41, females 68, age range 32-89 years) (25 cases Dukes' A, 22 cases Dukes' B, 28 cases Dukes' C and 34 cases of Dukes' D), and 106 cases of controls (males 50, females 56 , age range $26-85$ years) (60 healthy volunteers, 16 cases of chronic atrophic gastritis patients, and 30 cases of chronic superficial gastritis) were recruited for this study at the First Affiliated Hospital of Zhejiang University and Zhejiang Taizhou Municipal Hospital. The subjects were assigned into an experimental group and a verification group according to Table I. The peripheral blood samples were collected in the morning after overnight fasting. The blood samples were then maintained at $4^{\circ} \mathrm{C}$ for $1-2 \mathrm{~h}$ prior to centrifugation at $3,000 \mathrm{rpm}$ at $4^{\circ} \mathrm{C}$ for $10 \mathrm{~min}$ to separate out the serum. The serum samples were frozen at $-80^{\circ} \mathrm{C}$ in a freezer for storage. All protocols and experiments were approved by the Taizhou Medical College Ethics Committee for clinical experiments and use of human samples; written informed consent was obtained from all subjects participating in this study. The study complied with the World Medical Association Declaration of Helsinki regarding ethical conduct of research involving human subjects. 
Table I. Clinical subjects involved in the study.

\begin{tabular}{lccc}
\hline Groups & Experimental & Verification & Total \\
\hline Gastric adenocarcinoma & & & \\
Dukes' A & 15 & 10 & 25 \\
Dukes' B & 12 & 10 & 22 \\
Dukes' C & 20 & 8 & 28 \\
Dukes' D & 18 & 16 & 34 \\
Control & & & \\
Chronic superficial gastritis & 15 & 15 & 30 \\
Chronic atrophic gastritis & 8 & 8 & 16 \\
Healthy controls & 30 & 30 & 60 \\
Total & 118 & 97 & 215 \\
\hline
\end{tabular}

Protein chip analysis. After thawing and 10 min of centrifugation $(10,000 \mathrm{rpm})$, a $20-\mu 1$ serum sample without fraction treatment (which does not affect the protein mining efficiency as shown by the authors) was added to $30 \mu 10.5 \%$ U9 (9 mol/l urea, 2\% CHAPS (3[(3-cholamidopropyl)dimethylammonio]1-propanesulfonate), $1 \%$ DTT (DL-dithiothreitol)) in a 96-well plate and incubated for $20 \mathrm{~min}$ at $4{ }^{\circ} \mathrm{C}$ with $600 \mathrm{rpm}$ vigorous agitation. The ProteinChip array cassette was put into a 96-well bioprocessor and $100 \mu \mathrm{l} \mathrm{U1}$ buffer $(50 \mathrm{mmol} / \mathrm{l}$ Tris-HCL diluted 10\% U9 buffer) was added into each well, and incubated for $10 \mathrm{~min}$ at $4^{\circ} \mathrm{C}$ with $600 \mathrm{rpm}$ vigorous agitation. Q10 buffer $(200 \mu \mathrm{l})(100 \mathrm{mM}$ Tris-HCl buffer $\mathrm{pH} 9.0)$ was then added and a 5-min incubation was carried out 2 times with agitation. All experimental reagents were obtained from Shanghai Shenggong Company, Shanghai, China.

Fifty microliters of the protein-denatured serum samples were removed to a new tube, and $200 \mu \mathrm{l}$ Q10 buffer was added to dilute the samples before being applied onto the Q10 chip Bioprocessor (Ciphergen) for $60 \mathrm{~min}$. Then each plate of the Q10 chip was added together with $200 \mu \mathrm{l}$ Q10 buffer, incubation was carried out for $5 \mathrm{~min}$ two times with agitation, and finally 20 mm/1 HEPES (pH 7.4) buffer was added for washing before drying. SPA $(0.5 \mu 1)$ was added 2 times into each plate with drying between each addition. Mass spectrometry was set as laser intensity 185 , sensitivity $8,2,000-20,000 \mathrm{~m} / \mathrm{z}$. Interchip CV was $<10 \%$. All-in-one control chip was used to adjust the system with a systemic error $<0.1 \%$. All of the data were processed with ProteinChip 3.0 software, then the Biomarker Wizard software 3.1 and Biomarker Wizard software 4.0.1. $\mathrm{P}<0.01$ was determined to indicate statistically significant differences in the comparison between two protein peaks.

Purification and identification of specific protein peaks. Serum samples $(100 \mu \mathrm{l})$ with $300 \mu \mathrm{l}$ water and $700 \mu \mathrm{l}$ acetonitrile were mixed and maintained at $-20^{\circ} \mathrm{C}$ in a freezer for $30 \mathrm{~min}$ prior to centrifugation at $3000 \mathrm{rpm}$ for $10 \mathrm{~min}$. The supernatant was freeze-dried for $20 \mathrm{~min}$ before collection for HPLC. The purified solutions were collected at different time periods, freeze-dried to obtain a $20-\mu 1$ volume solution. Solution $(0.5 \mu \mathrm{l})$ was mixed with $1.5 \mu \mathrm{l}$ matrix solution (10 $\mathrm{mg} / \mathrm{ml} \mathrm{CHCA})$ to be placed on chip points, with crystallization for MALDI-TOF MS detection. The conditions
Table II. Intensity of the three differential peaks in gastric adenocarcinoma and control groups.

\begin{tabular}{lcrc}
\hline$(\mathrm{m} / \mathrm{z})$ & Gastric adenocarcinoma & \multicolumn{1}{c}{ Control } & P-values \\
\hline $5,907.5$ & $8.53 \pm 4.33$ & $0.88 \pm 0.31$ & $2.8 \times 10^{-7}$ \\
$6,636.7$ & $6.54 \pm 2.44$ & $17.56 \pm 4.43$ & $4.5 \times 10^{-6}$ \\
$8,716.3$ & $0.93 \pm 0.29$ & $2.16 \pm 0.98$ & $8.4 \times 10^{-4}$ \\
\hline
\end{tabular}

included pulsed nitrogen laser (337 nm), accelerating voltage $20 \mathrm{KV}$, linear analysis mode, mass range 3,000-20,000 m/z. The samples corresponding to the specific protein peaks in SELDI-TOF MS were subsequently identified.

LC-MS/MS analysis. Purified target protein of $20 \mu \mathrm{l}$ was mixed with $60 \mu \mathrm{l} 8 \mathrm{M}$ urea (final concentration of urea $6 \mathrm{M}$ ) and was agitated at room temperature for $20 \mathrm{~min}$. Then $0.8 \mu \mathrm{l} 1 \mathrm{M}$ DTT (final concentration $10 \mathrm{mM}$ ) was added and mixed at room temperature for $1 \mathrm{~h}$, and $3.2 \mu \mathrm{l} 1 \mathrm{M}$ iodine acetyl amine (final concentration $40 \mathrm{mM}$ ) was added and maintained for $45 \mathrm{~min}$ in the dark. DTT (3.2 $\mu 11 \mathrm{M})$ (final concentration $40 \mathrm{mM}$ ) was added for $20 \mathrm{~min}$, and then $400 \mu \mathrm{l} 50 \mathrm{mM} \mathrm{NH}_{4} \mathrm{HCO}_{3}$ was added to dilute the solution, with urea concentration at $1 \mathrm{M}$ and $\mathrm{pH}$ 8.0. Subsequently, $0.1 \mu \mathrm{g}$ protease in a $37^{\circ} \mathrm{C}$ water bath for $1 \mathrm{~h}$, and formic acid was adjusted to a $\mathrm{pH}<3$ to terminate the reaction. The hydrolysates were subjected to LC-MS/MS analysis. Sample solutions were put in a self-made $\mathrm{C} 18$ capillary column for liquid chromatography: inner diameter $100 \mu \mathrm{m}$, filled part $100 \mathrm{~mm}$, filled particles with diameter $5 \mu \mathrm{m}$. The flow phase A was water and $0.1 \%$ formic acid; the flow phase $\mathrm{B}$ was acetonitrile and $0.1 \%$ formic acid. The washout followed the sequences below: $100 \%$ A (0 min) - 100\% A (5 min) - 5\% B (5.1 min) - 65\% B (60 min) - $100 \%$ B (75 min) - 100\% B (85 min). The flow speed was $200-800 \mathrm{nl} / \mathrm{min}$. The data-dependent mode was used; the scanning ranges were from 400 to $2,000 \mathrm{~m} / \mathrm{z}$; the five strongest signal peaks of each full scan were selected for secondary MS (MS2) analysis.

The data retrieval used the XCalibur program components BioWorks 3.2 (Thermo Finnigan) and the peptide sequences were searched for in the NCBI human protein database (human.ref) according to the mass spectrum. The following parameters were used: enzyme split site at random site; fixed modification at cysteine amine formylation modification; variable modification at methionine oxidation; retrieval parameters $\Delta \mathrm{CN}>0.1 ; \mathrm{Sp}>500 ; \mathrm{Rsp} \geq 5$; Xcorr vs. Charge: Xcorr $(+1)>1.9$, Xcorr $(+2)>2.5$, Xcorr $(+3)>3.75$.

\section{Results}

The serum protein fingerprint spectrum. The protein fingerprint spectrum from 65 cases of gastric adenocarcinoma and 53 cases of control were normalized first, then analyzed using Biomarker wizard software. Two hundred and twenty-seven protein peaks were found in the $\mathrm{m} / \mathrm{z}$ range from 2,000-50,000 (Fig. 1).

Data analysis of the gastric adenocarcinoma protein fingerprint spectrum and the diagnostic model. The Biomarker Wizard software analysis revealed three differentially expressed 


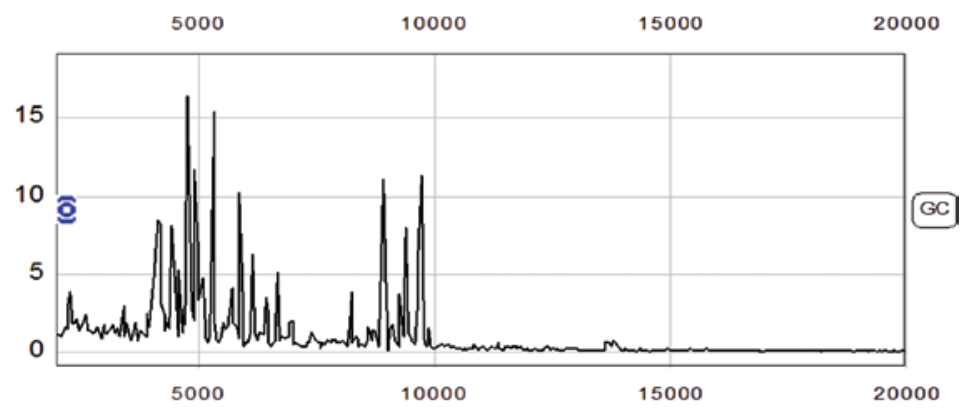

Figure 1. Serum proteomic spectrum of the gastric adenocarcinoma patients.
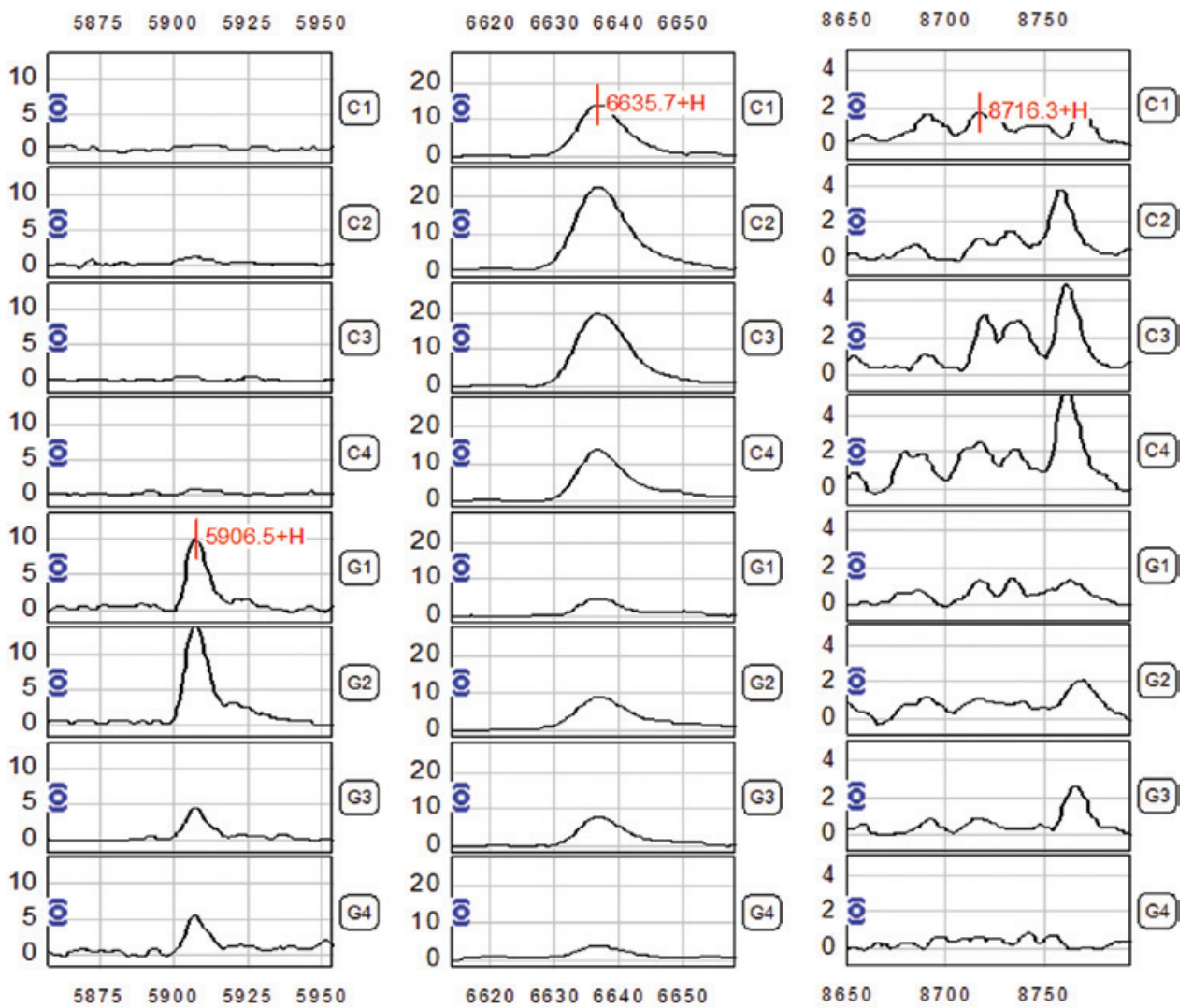

Figure 2. Protein fingerprint of the three protein peaks ( $\mathrm{m} / \mathrm{z} 5,906.5,6,635.7,8,716.3)$ for the diagnostic model of the gastric adenocarcinoma cases.
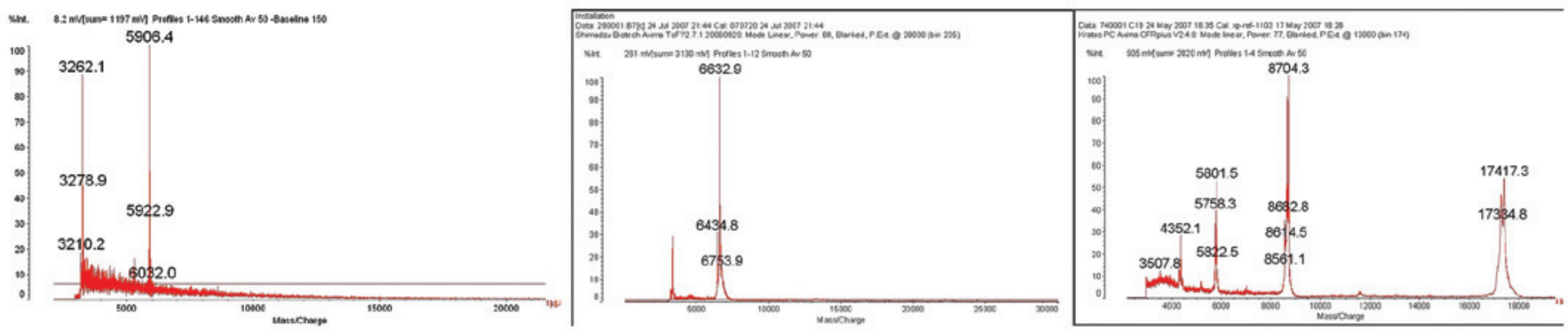

Figure 3. MALDI-TOF image of the three differential protein peaks $(\mathrm{m} / \mathrm{z} 5,906.5,6,637.6,8,716.3)$.

protein peaks in serum samples from gastric adenocarcinoma patients, with $\mathrm{m} / \mathrm{z}$ at 5,906.5, 6,635.7 and 8,716.3 respectively $(\mathrm{P}<0.01)$ (Fig. 2 and Table II), which were considered as poten- tial biomarkers for gastric adenocarcinoma. The 5,906.5 peak showed increased expression in the gastric adenocarcinoma cases; while the $6,635.7$ and 8,716.3 peaks showed a decreased 
Table III. Characteristics of the gastric adenocarcinoma diagnostic model.

\begin{tabular}{lllll}
\hline Set & \multicolumn{1}{c}{ Groups } & Case number & Correct cases & Diagnosis rate $(\%)$ \\
\hline Experimental & Gastric adenocarcinoma & 65 & 61 & 93.85 \\
& Control & 53 & 50 & 94.34 \\
Verification & Gastric adenocarcinoma & 44 & 40 & 90.91 \\
& Control & 53 & 48 & 90.57 \\
\hline
\end{tabular}

Table IV. Amino acid sequence of the differential protein peaks in the gastric adenocarcinoma cases.

\begin{tabular}{llll}
\hline$(\mathrm{m} / \mathrm{z})$ & \multicolumn{1}{c}{ Protein } & Molecular weight & \multicolumn{1}{c}{$\begin{array}{c}\text { Amino acid } \\
\text { sequence }\end{array}$} \\
\hline $5,906.5$ & Fibrinogen $\alpha$-chain & $5,904.0$ & $\begin{array}{l}\text { SSSYSKQFTS STSYNRGDST FESKSYKMAD } \\
\text { rate }(\%)\end{array}$ \\
& & & EAGSEADHEG THSTKRGHAK SRPV \\
$6,635.7$ & Apolipoprotein A-II & $6,630.0$ & TPDY SSALDKLKEF GNTLEDKARE \\
& & & LISRIKQSEL SAKMREWFSE TFQKVKEKLK IDS \\
$8,716.3$ & Apolipoprotein C-I & $8,707.8$ & QAK EPCV ESLVSQYFQT VTDYGKDLME \\
& & & $\begin{array}{l}\text { KVKSPELQAE AKSYFEKSKE } \\
\text { QLTPLIKKAG TELVNFLSYF VELGTQPATQ }\end{array}$ \\
\end{tabular}

expression level in the gastric adenocarcinoma serum samples (Table II). The combined analysis with the three peaks as the basis for the diagnostic model showed a sensitivity of 93.85 $(61 / 65)$ and a specificity of $94.34 \%(50 / 53)$ in analyzing the mass spectrometry data from the 65 gastric adenocarcinoma patients and 53 cases of control subjects (Table III).

Purification of the protein peaks and the MS analysis. The protein peaks of the three biomarkers (m/z 5,906.5, 6,635.7 and 8,716.3) were isolated and purified with HPLC, and then collected into PCR tubes for MALDI-TOF-MS examination. The results showed that the three peaks were proteins with molecular weights of 5,906.4, 6,632.9 and 8,704.3, respectively (Fig. 3).

Following LC-MS/MS measurement of the digested proteins and the data screening from NCBI human protein database, the 5,906.4 peak was found to correspond to the fibrinogen $\alpha$ chain (100\% match), the 6,632.9 peak corresponded to the apolipoprotein A-II (96\% match), and the 8,704.3 peak corresponded to the lipid-laden protein C-I $(60 \%$ match) (Table IV).

\section{Discussion}

Gastric cancer is a cancer without clear symptoms at onset, and metastasis and recurrence are common $(16,17)$. The prognosis of this disease is poor as well. Early diagnosis of gastric cancer urgently requires novel techniques with high sensitivity and specificity. Since the onset and progression of cancer lead to characteristic changes in the serum proteome, it is possible to employ proteomic techniques to screen for potential biomarkers of gastric cancer $(11,18,19)$. The present study utilized SELDI-TOF MS, and successfully identified a new diagnostic model for gastric cancer, including suitability for early-stage patients.

SELDI-TOF MS is an ideal platform for proteomic studies with several advantages. i) A small amount of sample is required. The scan is fast and suitable for clinical diagnosis and high throughput-screening analysis. ii) The technique can identify the specific spectrum including several biomarkers at the same time. iii) Crude samples without prior purification can be used. iv) The technique can be combined with many genomic techniques. v) The technique is of high reliability and can be reproduced in repeated tests. vi) The technique is applicable to proteins that are not suitable for 2D-PAGE analysis, such as those with extremely small molecular weights, or hydrophobic, transmembrane, as well as isoelectric point (8-10). The technique currently shows progressive results in biomarker screening of autoimmune diseases, inflammation disorders and many types of malignant cancers $(9,10,20-24)$, providing the basis for diagnosis and treatment of these diseases clinically.

The present study described three potential biomarkers for gastric cancer with high sensitivity and specificity in both the experimental and verification set, as mentioned in Results. The three identified markers were fibrinogen $\alpha$-chain, apolipoprotein A-II, and lipid-laden proteins C-I. They may play different roles in the onset and progression of gastric cancer. Fibrinogen participates in blood coagulation processes, and it may mediate the interaction of cancer cells and platelet, which occurs during cancer metastasis $(25,26)$. Apolipoprotein participates in lipid transport and may be involved in cell proliferation/apoptosis regulation $(27,28)$. C-I is mainly synthesized in the liver, and is less well-known in cancer biology. Several previous studies have shown a lower expression of C-I in serum from cancer patients $(29,30)$, which was consistent with the present study. However the detailed mechanism requires future studies. 
Taken together, the present study proved the efficiency of SELDI-TOF MS in screening for biomarkers of gastric cancer in a serum proteome-based manner. The three discovered biomarkers could be effectively used for gastric cancer diagnosis. Due to the limited number of patients, we did not perform a correlation analysis between the stage of cancer progression and the biomarker profiles. It is necessary to recruit more patients with early-stage disease to identify various biomarkers for the diagnosis of patients as early as possible.

\section{Acknowledgements}

The study was supported by the Zhejiang Medicine and Health Science and Technology Program grant 2010KYB127, and the Zhejiang Gongyi Applied Technology Research Program grant 2011C33045.

\section{References}

1. Jemal A, Bray F, Center MM, Ferlay J, Ward E and Forman D Global cancer statistics. CA Cancer J Clin 61: 69-90, 2011.

2. Parkin DM, Bray F, Ferlay J and Pisani P: Global cancer statistics, 2002. CA Cancer J Clin 55: 74-108, 2005.

3. Tseng CW, Yang JC, Chen CN, et al: Identification of 14-3-3beta in human gastric cancer cells and its potency as a diagnostic and prognostic biomarker. Proteomics 11: 2423-2439, 2011.

4. Kobayashi Y, Niwa Y, Tajika M, et al: Serum tumor antigen REG4 as a useful diagnostic biomarker in gastric cancer. Hepatogastroenterology 57: 1631-1634, 2010.

5. Yang S and Chung HC: Novel biomarker candidates for gastric cancer. Oncol Rep 19: 675-680, 2008.

6. Chan DC, Chen CJ, Chu HC, et al: Evaluation of serum amyloid A as a biomarker for gastric cancer. Ann Surg Oncol 14: 84-93, 2007.

7. Poon TC: Opportunities and limitations of SELDI-TOF-MS in biomedical research: practical advices. Expert Rev Proteomics 4: 51-65, 2007.

8. Cho WC: Research progress in SELDI-TOF MS and its clinical applications. Sheng Wu Gong Cheng Xue Bao 22: 871-876, 2006 (In Chinese).

9. Clarke $\mathrm{CH}$, Buckley JA and Fung ET: SELDI-TOF-MS proteomics of breast cancer. Clin Chem Lab Med 43: 1314-1320, 2005.

10. Liu C: The application of SELDI-TOF-MS in clinical diagnosis of cancers. J Biomed Biotechnol 2011: 245821, 2011.

11. Caffrey RE: A review of experimental design best practices for proteomics based biomarker discovery: focus on SELDI-TOF. Methods Mol Biol 641: 167-183, 2010.

12. Kristina G, Radomir P, Eva B, et al: When one chip is not enough: augmenting the validity of SELDI-TOF proteomic profiles of clinical specimens. Lab Chip 9: 1014-1017, 2009.
13. Liu W, Gao X, Cai Q, et al: Identification of novel serum biomarkers for gastric cancer by magnetic bead. Front Biosci (Elite Ed) 2: 961-971, 2010.

14. Huang Q, Chen W, Wang L, Lin W, Lin J and Lin X: Identification of transgelin as a potential novel biomarker for gastric adenocarcinoma based on proteomics technology. J Cancer Res Clin Oncol 134: 1219-1227, 2008.

15. Umemura H, Togawa A, Sogawa $\mathrm{K}$, et al: Identification of a high molecular weight kininogen fragment as a marker for early gastric cancer by serum proteome analysis. J Gastroenterol 46: 577-585, 2011.

16. Wang J, Yu JC, Kang WM and Ma ZQ: Treatment strategy for early gastric cancer. Surg Oncol: Jan 21, 2011 (Epub ahead of print).

17. Saka M, Morita S, Fukagawa T and Katai H: Present and future status of gastric cancer surgery. Jpn J Clin Oncol 41: 307-313, 2011.

18. Cho WC: Proteomics technologies and challenges. Genomics Proteomics Bioinformatics 5: 77-85, 2007.

19. Cho WC: Contribution of oncoproteomics to cancer biomarker discovery. Mol Cancer 6: 25, 2007.

20. Lei L, Wang XJ, Zheng ZG, et al: Identification of serum protein markers for breast cancer relapse with SELDI-TOF MS. Anat Rec (Hoboken) 294: 941-944, 2011.

21. Felix K, Fakelman F, Hartmann D, et al: Identification of serum proteins involved in pancreatic cancer cachexia. Life Sci 88: 218-225, 2011.

22. Liu L, Liu J, Wang Y, et al: A combined biomarker pattern improves the discrimination of lung cancer. Biomarkers 16: 20-30, 2011.

23. Hogdall E, Fung ET, Christensen IJ, et al: Proteomic biomarkers for overall and progression-free survival in ovarian cancer patients. Proteomics Clin Appl 4: 940-952, 2010.

24. Gemoll T, Roblick UJ, Auer G, Jornvall H and Habermann JK: SELDI-TOF serum proteomics and colorectal cancer: a current overview. Arch Physiol Biochem 116: 188-196, 2010.

25. Konstantopoulos K and Thomas SN: Cancer cells in transit: the vascular interactions of tumor cells. Annu Rev Biomed Eng 11: 177-202, 2009.

26. Costantini V and Zacharski LR: The role of fibrin in tumor metastasis. Cancer Metastasis Rev 11: 283-290, 1992.

27. Vanhollebeke B and Pays E: The function of apolipoproteins L. Cell Mol Life Sci 63: 1937-1944, 2006.

28. Ashe PC and Berry MD: Apoptotic signaling cascades. Prog Neuropsychopharmacol Biol Psychiatry 27: 199-214, 2003.

29. Engwegen JY, Helgason $\mathrm{HH}$, Cats A, et al: Identification of serum proteins discriminating colorectal cancer patients and healthy controls using surface-enhanced laser desorption ionisation-time of flight mass spectrometry. World J Gastroenterol 12: 1536-1544, 2006.

30. Fan Y, Wang J, Yang Y, et al: Detection and identification of potential biomarkers of breast cancer. J Cancer Res Clin Oncol 136: $1243-1254,2010$. 